\title{
Precisamos discutir o idadismo na comunicação
}

\author{
Gisela G. S. Castro \\ Docente e pesquisadora do Programa de Pós-Graduação Stricto Sensu em Comunicação e \\ Práticas de Consumo ESPM, São Paulo; coordena o Gruscco: Grupo CNPq de pesquisa em \\ subjetividade, comunicação e consumo. \\ E-mail: gcastro@espm.br
}

Resumo: Considerado por longo tempo um país de jovens, o Brasil apresenta hoje percentuais crescentes de adultos mais velhos. Esse progressivo amadurecimento da nossa população resulta da conjugação entre a expressiva redução nas taxas de natalidade e de mortalidade infantil, aliada ao significativo aumento da longevidade. Tais dados refletem o envelhecimento da população mundial, fato que torna importante o debate a respeito do idadismo. Esta é uma forma ainda pouco discutida de preconceito, baseado na idade, que ocasiona a discriminação contra as pessoas vistas como idosas e contribui para a sua marginalização e eventual exclusão social. Diante desse cenário em transformação, este artigo traz uma reflexão sobre a veIhice, promovendo uma discussão sobre o preconceito motivado pelos estereótipos associados à figura do velho em nosso meio social.

Palavras-chave: comunicação; idadismo; envelhecimento; velhice; preconceito.
Abstract: Brazil, for a long time considered a young country, shows nowadays decreasing percentage of adults and older people. This progressive maturation of our population results from the combination of the significant reduction in birth and infant mortality rates, coupled with the significant increase in longevity. These data reflect the ageing of world population, fact that is important to the debate on the ageism of older people, a yet little discussed form of prejudice, based on age, which leads to discrimination against people perceived as older, contributing to their marginalization and possible social exclusion. In this scenario of changes, this paper presents a reflection on old age, promoting a discussion about prejudice motivated by the stereotypes associated with the old people figure in our social context.

Keywords: ageism; aging; prejudice; communication.

\section{INTRODUÇÃO}

O envelhecimento da população mundial torna imperioso o debate sobre a velhice e coloca em questão o idadismo, uma forma ainda muito pouco discutida de preconceito baseado na idade que ocasiona a discriminação contra as pessoas vistas como idosas e contribui para a sua marginalização e eventual exclusão social. 
1 BORGES, G. M.; CAMPOS, M. B.; SILVA, L. G. C. Transição da estrutura etária no Brasil: oportunidades e desafios para a sociedade nas próximas décadas. In: ERVATTI, L. G.; BORGES, G. M.; JARDIM, A. P. Mudança demográfica no Brasil no início do século XXI: subsídios para as projeções da população. IBGE, 2015, p. 146

2 BEAUVOIR, S. A velhice: a realidade incômoda. São Paulo: Difel, 1976.

3 Idem, p. 5.

4 DEBERT, G. G. A reinvenção da velhice: socialização e processos de reprivatização do envelhecimento. São Paulo: Edusp, 1999.

5 Idem, p. 12.
Conforme já acontece em outras partes do mundo, mesmo no Brasil, que por longo tempo foi considerado um país jovem, a representação gráfica da distribuição da população por idade já não configura uma pirâmide com ampla base de recém-nascidos, crianças e jovens e percentuais decrescentes de adultos e idosos.

Motivado pelo desenvolvimento social do país, o progressivo amadurecimento da nossa população resulta da conjugação entre a expressiva redução nas taxas de natalidade e de mortalidade infantil, aliada ao significativo aumento da longevidade. Nesse contexto em que nascem menos bebês e vive-se por mais tempo,

O segmento populacional que mais aumenta na população brasileira é o de idosos, com taxas de crescimento de mais de $4 \%$ ao ano no período de 2012 a 2022. [...] Espera-se, para os próximos 10 anos, um incremento médio de mais de 1,0 milhão de idosos anualmente ${ }^{1}$.

Os dados referentes ao tempo médio de vida do brasileiro demonstram um acréscimo superior a 11 anos entre 1980 e 2013. Pelas projeções feitas pelo IBGE citadas acima, em poucas décadas teremos um percentual de idosos no Brasil semelhante ao do Japão, país que hoje proporcionalmente detém o maior contingente de velhos em sua população.

Diante desse cenário em transformação, não podemos deixar de refletir sobre a velhice e promover uma discussão sobre o preconceito motivado pelos estereótipos associados à figura do velho em nosso meio social.

\section{A VELHICE COMO FATO CULTURAL}

Em obra que se tornou referência, Simone de Beauvoir² (1976) relata ter entreouvido no comentário de uma aluna norte-americana a palavra "velha" pela primeira vez associada à sua pessoa. Instigada pelo efeito perturbador da associação que considerou incômoda no vigor dos seus 50 anos à época, Beauvoir empreendeu minucioso estudo no qual põe em questão a naturalização da velhice como fato biológico, denuncia a ambiguidade do termo e constata ser "impossível encerrar esta pluralidade de experiências num conceito ou numa noção". Ao defender que a velhice deve ser entendida como um "fato cultural", a autora conclamou os leitores à luta contra a "conspiração do silêncio" usada para escamotear o descaso de nossas sociedades em relação aos mais velhos.

A veterana estudiosa Guita Debert ${ }^{4}$ reconhece a influência das reflexões da intelectual francesa em seu trabalho. Ao analisar as mudanças culturais em andamento no Brasil, a autora percebe que em parte devido ao envelhecimento populacional com o qual nos deparamos neste país, o idoso não está mais ausente dos discursos públicos. Entretanto, segundo argumenta:

explicar por razões de ordem demográfica a aparente quebra da "conspiração do silêncio" em relação à velhice é perder a oportunidade de descrever os processos por meio dos quais o envelhecimento se transforma em um problema que ganha expressão e legitimidade, no campo das preocupações sociais do momento ${ }^{5}$. 
Mirian Goldenberg ${ }^{6}$ também admite a influência de Beauvoir em suas pesquisas sobre os modelos de velhice no Brasil atual. No seu entender, a discussão dos resultados gerados por estudos empíricos junto a homens e mulheres de diferentes segmentos sociais visa dar a conhecer os modos pelos quais a sociedade brasileira experimenta e confere sentido ao processo de envelhecimento. Sua argumentação sobre os imperativos, sofrimentos e significados relacionados vivenciados pelos adultos mais velhos privilegia a investigação das questões de gênero, do corpo como capital e os diferentes modos de perceber e experimentar a velhice em nossos dias.

Juntamente com o pensamento crítico, a complexidade do processo de envelhecimento demanda o aguçamento da sensibilidade de modo a detectar zonas negativas de conflito, angústia e sofrimento, ao mesmo tempo em que se possa evidenciar a positividade nas transformações operadas pelo amadurecimento e a experiência de vida.

Segundo Debert, levar em consideração os modos vigentes de gestão da velhice implica procurar compreender, por exemplo, de que maneira as representações sobre o envelhecimento "rearticulam projetos de vida, trabalho e lazer de grupos em diferentes faixas etárias" ção da questão da velhice por meio de intervenções das políticas públicas e com o desenvolvimento de um campo de conhecimento especializado como a gerontologia, instaura-se de modo paradoxal o que a pesquisadora denomina como a "reprivatização da velhice", transformada em uma questão de responsabilidade individual. Para Goes" "se o indivíduo goza de saúde física, mental e financeira [...], tende a prolongar seu processo de envelhecimento com bem-estar e em paz". Para Leal ${ }^{9}$ :

A velhice não é só biológica, é biográfica, cada pessoa tem a sua história de desenvolvimento que deve ser levada em consideração e "envelhecer bem" é subjetivo, nunca será igual para todos.

Na ressignificação em curso nos modos de vivenciar e representar a velhice, os estereótipos negativos associados a esta fase da vida — os quais entre nós deram origem à expressão "terceira idade" e eufemismos como "melhor", "maior" ou mesmo "feliz" idade — são crescentemente desafiados pelo modelo positivo da velhice ativa, gratificante e jovial frequentemente associada a estilos de vida e padrões de consumo considerados adequados e que se tornaram uma exigência.

"Meia-idade", "terceira idade", "aposentadoria ativa" são categorias empenhadas na produção de novos estilos de vida e na criação de mercados de consumo específicos. Rompendo com as expectativas tradicionalmente associadas aos estágios mais avançados da vida, cada uma destas etapas passa a indicar, a sua maneira, fases propícias para o prazer e para a realização de sonhos adiados em momentos anteriores ${ }^{10}$.

Consoante com os ensinamentos de Beauvoir, Debert e Goldenberg, dentre outros estudos, entendemos ser a velhice uma experiência multifacetada e uma categoria de referência imprecisa e mesmo dúbia. É um equívoco supor que esteja atrelada a uma suposta cronologia fixa de marcadores etários. De modo
6 GOLDENBERG, M. A bela velhice. Rio de Janeiro: Record, 2013 e idem (org.). Corpo, envelhecimento e felicidade. Rio de Janeiro: Civilização Brasileira, 2011.

7 DEBERT, G. G., op. cit., p. 12.

8 GOES, T. A velhice em novos tempos. Revista E. Sesc-SP, v. 20, n. 1, 2013, p. 43.

9 LEAL, M. G. S. Aspectos psicológicos do envelhecimento. Entrevista à Revista E. Sesc-SP, v. 20, n. 1, 2013, p. 44.

10 DEBERT, G. G. op. cit., 1999 , p. 45. 
semelhante, é ingênuo tomá-la como um fenômeno natural apenas decorrente da inexorável passagem dos anos no decurso da vida.

Para além de suas determinações cronológicas, demográficas e biológicas, a velhice é uma construção sociocultural marcada por uma ampla série de fatores de ordem econômica, familiar, de gênero, de estilo de vida, para citar apenas algumas variáveis dessa delicada construção. Nesse contexto do envelhecimento das populações em todo o mundo, é mais do que necessário reconhecer a dimensão sociocultural da velhice. Featherstone e Hepworth ${ }^{11}$, chamam a atenção para a necessidade de explorarmos os modos como os discursos sobre o envelhecimento passaram a fazer parte significativa das culturas popular e de consumo. Nesse contexto, os autores enxergam a preocupação latente na proposta do envelhecimento positivo (positive aging), que seria um contraponto à constatação de que nossa sociedade discrimina o velho por meio do preconceito do idadismo (ageism), que aciona atitudes nas quais se mesclam condescendência e negligência em relação aos mais velhos.

\section{A VELHICE COMO CATEGORIA IMPRECISA}

Não há consenso sobre quando exatamente devemos começar a ser classificados como velhos. O Estatuto do Idoso em vigor trata dos direitos dos brasileiros em idade igual ou superior a 60 anos. Nossa Previdência Social concede aposentadoria para homens a partir 65 anos e para as mulheres com 60 anos ou mais; porém, é sabido que tais parâmetros estão em permanente contestação e são alvos de renhidas disputas entre instâncias diversas de nossa sociedade e governo. Evidentemente, a idade cronológica se articula com outras categorias de classificação e normatização social. Não se trata de um conceito estático, está sujeito a variadas definições de acordo com o contexto. Compreende-se assim a dificuldade de precisar, de modo definitivo, em que idade se atinge velhice, que não deve ser pensada como um patamar cronologicamente estável.

Aliada à imprecisão do conceito, no conjunto de signos sociais em circulação a velhice costuma ser mais comumente definida em termos de seu contrário como perda do vigor da juventude. Assim, configura-se no imaginário como um estágio de decadência, vulnerabilidade e risco. No senso comum, a progressiva fragilidade que acompanha a senescência assusta mais do que a

11 FEATHERSTONE, M.; HEPWORHT, M. Images of Positive Ageing: A Case Study of Retirement Choice magazine. In: FEATHERSTONE, M.; WERNICK, A. (eds.). Images of Aging: Cultural Representations of Later Life. Londres: Routledge, 1995, pp. 29-47.

12 DEBERT, G. G., 1999, p. 29. morte propriamente dita, apesar do horror que nos provoca acercar-nos de nossa própria finitude.

Sendo o valor social atribuído ao velho que se mantém jovem e ativo, a velhice raramente comparece como uma categoria de autoidentificação. Para Beauvoir, a velhice é o outro. Guita Grin Debert chama a atenção para esse fato ao constatar em suas pesquisas de cunho etnográfico que também no Brasil "velho é sempre o outro" ${ }^{2}$. É provável que isso se deva a uma percepção de que, ao negarmos a nossa própria velhice, evitaríamos o estigma negativo e a dose de ostracismo social que estaria implícita nessa categorização. 


\section{A TERCEIRA IDADE E A MEDIAÇÃO DO CONSUMO}

Peter Laslett, ao tratar da terceira idade em obra influente dos anos 1980, advoga a necessidade de uma compreensão mais refinada do envelhecimento - e notadamente da aposentadoria, que passa a ser ressignificada como o momento privilegiado em que se teria conquistado o direito de se dedicar a atividades voltadas mais exclusivamente para o desfrute da vida. Nesse estudo empreendido pelo autor aos sessenta e poucos anos, Laslett propõe decompor a categoria "idade" em seus diferentes componentes de análise. Como resultado dessa operação, temos a idade cronológica, a idade biológica, a idade social, a idade pessoal e, finalmente, a idade subjetiva.

Reconhecemos que as relações entre a idade social e a idade biológica costumam ser complexas e fazem parte das disputas simbólicas que caracterizam nossas sociedades. Em relação ao descompasso por vezes experimentado pelos mais velhos entre as idades pessoal e subjetiva, recorremos aos estudos de Featherstone e Hepworth ${ }^{13}$, para quem a "máscara da idade" é vivenciada como uma perturbadora espécie de "traição" do corpo que se torna incapaz de corroborar a imagem mental do self que foi cristalizada subjetivamente como juvenil. Esse argumento nos remete à discussão mencionada anteriormente sobre a vivência do velho como outro, mesmo que este outro o seja em relação a si próprio.

Críticas feitas às análises de Laslett $^{14}$ sintetizadas acima destacam que o autor toma como universais os padrões e costumes da classe média. Hoje se entende a terceira idade como uma categoria construída de modo mais evidente pela mediação do consumo, instância que nomeia o nosso tempo como a era do consumo ${ }^{15}$. As múltiplas inter-relações entre comunicação e consumo caracterizam a experiência contemporânea e constituem um instigante campo de estudos com o qual este trabalho dialoga.

Nesta prevalência das dinâmicas do consumo na esfera social, ocorre o esfumaçamento dos limites que tradicionalmente separavam e, simultaneamente, caracterizavam as etapas da vida e fixavam padrões identitários e de comportamento que seriam apropriados para cada etapa. Hoje temos uma situação na qual predominam os estilos de vida selecionados segundo padrões e preferências de consumo. Nesse ideário, a juventude se apresenta como um valor a ser mantido e exibido - em qualquer idade. No ordenamento social promovido pelas lógicas de consumo, constata-se que "a promessa da eterna juventude é um mecanismo fundamental de constituição de mercados de consumo"16.

A segmentação operada por esses mercados de consumo utiliza os 50 ou 55 anos como idade de corte para classificar o consumidor como idoso. Parece problemático pretender englobar em um só estrato a enorme diversidade de perfis de comportamento entre indivíduos de 50, 60, 70, 80, 90 anos — incluindo-se ainda os centenários, que já não são tão raros entre nós. Na ressignificação dos modos de vivenciar e representar a velhice como "melhor", "maior" ou mesmo "feliz" idade, sugere-se o modelo da velhice ativa e gratificante contra arraigados estereótipos negativos comumente associados à velhice. Esse modelo
13 FEATHERSTONE, M.; HEPWORHT, M. op. cit.

14 LASLETT, P. A Fresh Map of Life: The Emergence of the Third Age. Londres: Weidenfeld and Nicolson, 1989.

15 ALONSO, L. E. La era del consumo. Madri: Siglo XXI, 2005.

16 DEBERT, G. G., 1999, p. 33. 
positivo é associado a estilos de vida baseados no consumo de bens e serviços considerados adequados e desejáveis.

Nas individualizadas e flexíveis formações identitárias que caracterizam a atualidade, prevalece de um modo geral o ideário do "envelhecer bem" associado ao manter-se ativo, bem disposto - e jovem. No binarismo normativo e hierárquico entre velhos e não velhos que permeia a construção social da juventude como padrão desejável, os jovens estão associados a atributos como saúde, jovialidade e beleza. Para os mais velhos, reservam-se as conotações desagradáveis, como a fragilidade física e/ou mental na senescência e a incapacidade de cuidar de si próprio.

Nessa concepção hipertrofiada de juventude como valor, este é um atributo a ser preservado em qualquer idade como sinônimo de "boa" saúde. O envelhecimento passa a ser visto como algo contra o qual se torna imperioso lutar. Saúde, boa forma física (fitness) e beleza formam um todo indissociável que fundamenta a noção de bem-estar e movimenta sobremaneira as dinâmicas do consumo. Especialmente no que diz respeito à aparência, e mais diretamente em relação às mulheres, não combater os efeitos do tempo e "deixar-se envelhecer" se confunde com lassidão moral. Apesar de frequentemente serem bem-intencionados, os esforços para manter o envelhecimento "bem-sucedido" podem se transformar em insensatez e tirania social.

Mais recentemente, o interesse no potencial de consumo do público mais velho enseja certa profusão na mídia de imagens positivas da velhice. Como se viu, essa fase da vida é frequentemente alardeada como um período gratificante, a "terceira" e "melhor" idade. Por estarem livres das obrigações do trabalho e da criação dos filhos, poderiam enfim dedicar-se aos cuidados pessoais - comumente relacionados às diversas tecnologias do rejuvenescimento, aliadas ao vestuário e acessórios da moda - e a projetos longamente adiados, tais como viajar ou aprender sobre vinhos. Em geral essas imagens apresentam indivíduos de meia-idade em excelente forma física, aparentando desfrutar de um estado perpétuo de lazer e puro deleite.

Nesse tipo de estratégia criativa das narrativas do consumo, são frequentes as alusões às gratificações e prazeres da socialização, o que não raro inclui os relacionamentos amorosos entre pessoas maduras. Entra em cena o que Debert e Brigueiro ${ }^{17}$ denominam como a "erotização da velhice", sendo a sexualidade "um dos pilares do envelhecimento ativo, modelo de gestão do envelhecimento mais generalizado no mundo contemporâneo" (grifo no original).

17 DEBERT, G.; BRIGUEIRO, M. Fronteiras de gênero e a sexualidade na velhice. Revista Brasileira das Ciências Sociais, v. 27 , n. 80,2012 , p. 37.

\section{OS BABY BOOMERS ESTÃO ENVELHECENDO}

Nascida no pós-Segunda Grande Guerra, a geração baby boomer compreende contingentes de indivíduos, muitos dos quais são hoje septuagenários. O estudo da construção social dos modos de ser e de doar sentido às diferentes etapas do ciclo da vida adquire especial significado quando se focaliza uma geração que 
de certa forma fundou um modelo de juventude até hoje considerado emblemático. Trata-se de um grupo populacional que protagonizou transformações históricas em nossa sociedade. Goldenberg ${ }^{18}$ descreve essa geração como sendo composta por

[...] homens e mulheres que passaram por importantes mudanças na sociedade ou mesmo tiveram participação ativa nelas, tais como o movimento feminista, as mudanças no comportamento sexual, os novos modelos de casamento e de família, a entrada maciça das mulheres nas universidades e no mercado de trabalho, o uso da pílula anticoncepcional, a vivência de terapias psicológicas e psicanalíticas, o movimento da contracultura, a lei do divórcio, entre tantas transformações que ocorreram nos anos 1960 e nas décadas seguintes.

Alinhados com essa perspectiva, Featherstone e Hepworth ${ }^{19}$ salientam que não seria razoável que os jovens frutos dessas intensas transformações envelhecessem segundo os mesmos padrões das gerações que os antecederam. Os protagonistas da cultura jovem - dos movimentos de contracultura e também contemporâneos da massificação do consumo - trariam para a maturidade estilos de vida marcados pelo presenteísmo e individualismo que de certo modo caracterizam o contemporâneo.

Como ressaltam os autores, em análise que se tornou referência na sociologia do envelhecimento, observa-se:

[...] uma crescente sensibilidade por parte dos negociantes acerca dos potenciais novos mercados constituídos pela vida na meia-idade e além. [...] Na sociedade contemporânea, não são apenas os mais jovens que são encorajados a desenvolverem um interesse na moda, nos modos de apresentação de si e na construção e reconstrução das expressões do self por meio de estilos de vida individualistas através dos bens de consumo, mas também aqueles acima dos $50 \operatorname{anos}^{20}$.

Evidentemente, essa afirmação deve ser aqui relativizada de modo a se evitar incorrer em generalizações equivocadas e injustificadas. O próprio uso da categoria geração precisa ser posto em questão de modo a se enfatizar não apenas a diversidade de estilos e modos de ser entre coetários, como também para chamar a atenção para o estreitamento dessas categoria nas atuais configurações de família que passam a coexistir com a tradicional família nuclear. A passagem de avô para pai e deste para filho e neto não é mais necessariamente tão claramente demarcada quando se pensa nos arranjos familiares em que se promove a convivência entre proles de diferentes casamentos de genitores e progenitores.

Convivemos com diferentes modelos de jovens, adultos, velhos e idosos. Ao lado do vovô clássico de cabelos brancos temos o motoqueiro tatuado que já é avô e vira pai novamente. É justamente nessa riqueza simbólica que encontramos elementos para constituir a atribuição de sentidos para o envelhecimento. Conforme será visto a seguir, o preconceito do idadismo nem sempre comparece de modo explícito nas atitudes e nos discursos em relação aos mais velhos. Pode estar presente, mesmo que de modo velado, tanto na esfera cotidiana das
18 GOLDENBERG, M., op. cit., 2011.

19 FEATHERSTONE, M.; HEPWORTH, M., op. cit..

20 No original: "An important force behind the emergence of popular images of positive aging, the 'ageing industry' [...] is a growing sensitivity on the part of merchandisers to the potential new market in middle and later life. [...] In contemporary society it is not only the young who are encouraged to develop an interest in fashion, presentation of self and the continuous construction and reconstruction of an individualistic self-expressive lifestyle through consumer goods [...], but over-50s as well" (Featherstone; Hepworth, op. cit., pp. 32-33). 
interações interpessoais quanto nas produções midiáticas que circulam nos mais diversos meios de comunicação.

\section{O INSIDIOSO IDADISMO}

A desvalorização do velho em nossas sociedades está diretamente relacionada com os pre(con)ceitos do idadismo. O idadismo (em inglês, ageism) é uma das formas insidiosas de preconceito que acarreta a discriminação por idade. Apesar de disseminado, o idadismo é ainda muito pouco discutido tanto por estudiosos do meio acadêmico quanto pelos meios de comunicação. No entanto, como veremos com mais detalhe adiante, no rol das questões sociais que merecem atenção e apoio, a luta contra o idadismo por meio da promoção de imagens positivas dos mais velhos na mídia faz parte da agenda de recomendações da ONU para o conturbado cenário do envelhecimento da população mundial. Dentre as dez "ações prioritárias" para maximizar as oportunidades para as populações que estão envelhecendo no mundo todo, o Relatório do Fundo de Populações das Nações Unidas (UNFPA) ${ }^{21}$, documento elaborado em 2012, recomenda o

Desenvolvimento de uma nova cultura do envelhecimento baseada em direitos humanos, com uma mudança de mentalidade e atitudes sociais relacionadas ao envelhecimento e às pessoas idosas [...]. Isto requer [...] medidas afirmativas que contestem a discriminação por idade e reconheçam os idosos e idosas como indivíduos autônomos.

Diversas recomendações da ONU dizem respeito aos meios de comunicação, como veremos com maior detalhe no próximo tópico. Estereótipos negativos associados ao idadismo acionam atitudes nas quais se mesclam, muitas vezes de modo inconsciente, graus variados de condescendência e/ou de negligência em relação aos mais velhos. A problemática infantilização do idoso é uma dessas formas estereotipadas de se relacionar com os mais velhos. Travestida de carinho diante da fragilidade da situação de dependência, essa forma de tratamento frequentemente dispensado por cuidadores e profissionais de saúde atinge a dignidade do mais velho ao destituir-lhe do status de pessoa adulta.

21 Disponível em: <www. unfpa.org/sites/default/ files/pub-pdf/PortugueseExec-Summary_0.pdf>. Acesso em: ago. 2015.

22 NERI, A. L. Atitudes e preconceitos em relação à velhice. In: NERI. A. L. (org.). Idosos no Brasil: vivências, desafios e expectativas na terceira idade. São Paulo: Fundação Perseu Abramo/ Sesc-SP, 2007, p. 38.
O paternalismo condescendente frequentemente dispensado aos mais velhos pode ter como pressuposto implícito o estereótipo que realça a dependência dos mais velhos. Anita Neri argumenta que

longe de ajudar os idosos, os estereótipos compassivos podem contribuir para a criação e o fortalecimento de novas avaliações negativas e de novos estereótipos, prejudiciais aos seus interesses ${ }^{22}$.

O desrespeito ao idoso pode ser constatado ainda em certas produções midiáticas onde sua imagem é acionada na tênue fronteira entre o humor e o escárnio. Não é incomum que o humor autodepreciativo revele o preconceito 
do idadismo entre os próprios idosos, que não estão imunes às mesmas pressões sociais que constituem significados negativos em relação à velhice.

Quando todos são instados a querer ser e parecer jovens, o envelhecimento se torna um problema e seus sinais passam a ser encarados como erro. São abundantes os reality shows de transformação da imagem pessoal que promovem a pedagogia social do rejuvenescimento. Tampouco é infrequente nas cintilantes imagens digitais de celebridades intervenções estéticas que desafiam a prudência e o bom senso.

Em estudo qualitativo sobre a vivência do envelhecimento em diferentes grupos sociais, Slevin ${ }^{23}$ constatou que o medo de envelhecer atinge tanto os homens quanto as mulheres. Entretanto, mais do que os homens, as mulheres temem exibir uma aparência envelhecida, e o corpo jovem e esbelto considerado belo funciona como capital social. Frequentemente elas se sentem compelidas a se engajar nas árduas disciplinas e rotinas da dietética e da cosmética antienvelhecimento. De modo semelhante, grupos de gays masculinos tendem a valorizar sobremaneira a aparência física atrelada ao ideário fitness. Evidentemente, a preocupação masculina com a aparência e a boa forma física não mais se resume ao público gay e tem sido fortemente estimulada por crescentes investimentos de uma retórica de cunho persuasivo que equaciona boa aparência, bem-estar e qualidade de vida e constitui o mercado consumidor. Pode-se argumentar que o idadismo é escamoteado na promoção desse ideário.

Combater o preconceito significa desafiar estereótipos e visões arraigadas que nos impedem de celebrar a diversidade e as diferenças que nos caracterizam como seres humanos. Combatendo a discriminação fomentamos novas formas de convívio social, incluindo as interações baseadas no respeito e na solidariedade entre gerações.

\section{A REVOLUÇÃO DA LONGEVIDADE E AS PROPOSTAS DA ONU PARA OS MEIOS DE COMUNICAÇÃO}

A chamada revolução da longevidade diz respeito não apenas à comprovação de que um maior número de pessoas está vivendo mais, como também está relacionada à diminuição das taxas de natalidade vigentes. A combinação desses fatores resulta numa expansão sem precedentes das faixas etárias mais avançadas, redesenhando de modo contundente a pirâmide demográfica mundial.

Os dados projetados pela Organização das Nações Unidas revelam que a proporção de pessoas com 60 anos ou mais em todo o mundo irá duplicar nas próximas décadas, devendo alcançar a marca de 2 bilhões até 2050. Dentre os idosos, a faixa populacional que mais cresce é aquela que compreende os indivíduos acima de 80 anos. Tendo sido contabilizados em 70 milhões no ano 2000, estima-se que venham a quintuplicar ao longo da primeira metade deste século.
23 SLEVIN, K. F. "If I Had Lots of Money... I'd Have a Body Makeover": Managing the Aging Body. Social Forces, v. 88, n. 13, 2010. 
Ainda segundo a ONU, 64\% de todas as pessoas mais velhas vivem em regiões menos desenvolvidas do mundo. Em 2050 essa proporção deverá aproximar-se de $80 \%$, com um rápido e significativo crescimento de 8 para $19 \%$ no total de idosos nas populações de países menos desenvolvidos. Diante dos enormes desafios representados por essas projeções, no intuito de chamar a atenção para a temática e auxiliar na elaboração de políticas públicas para as populações idosas em todo o mundo, a Primeira Assembleia Mundial sobre o Envelhecimento foi convocada no ano de 1982. O Plano de Ação produzido nesse evento elencava 62 pontos de atenção, tais como saúde e nutrição, proteção de consumidores idosos, habitação e meio ambiente, família, bem-estar social, segurança de renda e emprego, educação etc.

Em 1991, a Assembleia Geral adotou o Princípio das Nações Unidas em Favor das Pessoas Idosas. Esse documento enumerava 18 direitos básicos que dizem respeito a independência, participação, cuidado, realização pessoal e dignidade do idoso em nossas sociedades. No ano seguinte, a Conferência Internacional sobre o Envelhecimento consolidou o Plano de Ação e recomendou que a Assembleia Geral da ONU declarasse 1999 como o Ano Internacional do Idoso.

Com o tema "Sociedade para Todas as Idades", o Ano Internacional do Idoso gerou reflexões em torno de quatro áreas principais: a) desenvolvimento pessoal ao longo da vida; b) relacionamentos entre gerações; c) as inter-relações entre envelhecimento populacional e desenvolvimento; d) a situação dos idosos.

Em 2002, a Segunda Assembleia Mundial sobre o Envelhecimento ocorreu em Madri. Nesse encontro foi produzida uma Declaração Política e um Plano Internacional de Ação sobre o Envelhecimento, documento que ficou conhecido como o Plano de Madri e funcionou como um marco para todas as diretrizes subsequentes. Em 2013, o Secretário Geral das Nações Unidas renovou o apelo para "garantir a integração social das pessoas mais velhas e que a promoção e proteção de seus direitos forme parte integral da agenda de desenvolvimento em nível nacional e global"24.

O Plano de Madri ${ }^{25}$ entende o envelhecimento populacional como base para o desenvolvimento social no futuro. Chamando a atenção para a necessidade de se fomentar a pesquisa sobre a temática, recomenda-se a elaboração de políticas públicas voltadas para a inclusão social do idoso e a promoção de oportunidades para o desenvolvimento de um mundo menos desigual no que

24 Trecho citado no documento World Population Ageing 2013, ONU. Disponível em: <www.un.org/ en/development/desa/ population/publications/ pdf/ageing/WorldPopu lationAgeing2013.pdf > . Acesso em: ago. 2015.

25 Versão em português disponivel em: <www. observatorionacionaldoi doso.fiocruz.br/bibliote $\mathrm{ca} /$ manual/5.pdf $>$. Acesso em: ago. 2015. tange ao respeito aos mais velhos. O objetivo é articular a questão do envelhecimento nas iniciativas de promoção do desenvolvimento econômico e social, bem como na agenda dos direitos humanos. A dimensão pública da velhice demanda uma série de orientações e intervenções por parte dos aparelhos de Estado e organizações públicas e privadas. As recomendações priorizam três aspectos: a) a participação dos mais velhos no processo de desenvolvimento; b) a promoção da saúde e bem-estar na velhice; c) a criação de ambiente propício e favorável.

Neste último quesito, as recomendações se voltam para a participação do idoso no desenvolvimento social e propõem uma maior cooperação entre países desenvolvidos e em desenvolvimento com o objetivo de garantir que possam 
ser cumpridas as metas estabelecidas na Declaração do Milênio ${ }^{26}$ em relação à erradicação da pobreza no mundo globalizado. Reconhece-se ainda, nesse aspecto, a necessidade de promover uma sociedade mais inclusiva e coesa para homens e mulheres; crianças, jovens e pessoas mais velhas.

O Plano de Madri enfatiza a luta contra a discriminação e o preconceito em relação ao idoso. Dentro da Orientação Prioritária Quatro ("Promoção de ambiente favorável e propício”), interessa mais à pesquisa o Tema IV — Imagens do Envelhecimento. No conjunto de medidas propostas para promover o reconhecimento público das contribuições e atributos dos mais velhos, o plano confere aos meios de comunicação um papel de destaque conforme pode ser constatado na seleção apresentada a seguir:

d) estimular os meios de comunicação a transcender a apresentação de estereótipos e ilustrar a diversidade plena da humanidade;

e) reconhecer que os meios de comunicação são precursores da mudança e podem atuar como fatores de orientação na promoção do papel que toca aos idosos nas estratégias de desenvolvimento [...];

f) facilitar as contribuições de homens e mulheres idosos na apresentação de suas atividades e preocupações por parte dos meios de comunicação;

g) estimular os meios de comunicação [...] a evitar a discriminação por razão da idade $[. .$.$] e apresentar imagens positivas de pessoas mais velhas" { }^{27}$.

As transformações em curso na composição populacional e a consolidação da gerontologia - área multidisciplinar que congrega as ciências da saúde e as ciências sociais e humanas em torno de estudos sobre o envelhecimento e atua na defesa dos interesses e direitos dos mais velhos - contribuem para situar a velhice no debate público e promover a disseminação de novas imagens positivas do envelhecimento no campo social.

Produtos de complexos processos afetivos e sociocognitivos, "as atitudes em relação à velhice são socialmente aprendidas ao longo de toda a vida"28. Essa aprendizagem se dá pela experiência direta da vivência da própria velhice e/ ou de modo indireto por meio da convivência com idosos nas diversas esferas sociais. Variadas modalidades de experiência simbólica também concorrem para esse tipo de aprendizagem — daí o papel importante dos meios de comunicação na produção de sentidos.

Ao lançar mão da Teoria das Mediações para situar os meios de comunicação no próprio tecido social, Tony Benett ${ }^{29}$ problematiza a noção reflexionista dos regimes de representação que tomam a mídia como espelho. No trecho a seguir, o autor levanta a questão do enquadramento midiático ao examinar o controverso argumento sobre o papel da mediação promovida pelos meios de comunicação na própria definição da realidade social:
26 Fruto de Resolução da Assembleia Geral das Nações Unidas assinada no ano 2000, a Declaração estabelece um pacto de cooperação internacional em torno dos seguintes valores fundamentais: liberdade, igualdade, solidariedade, tolerância, respeito à natureza, responsabilidade compartilhada. Disponível em: <www.un.org/ millennium/declaration/ ares552e.htm>. Acesso em: ago. 2015.

27 Plano de Madri, p. 71 28 NERI, op. cit., p. 35.

29 BENNETT, T. Media, "Reality", Signification. In: GUREVITCH, M., BENNETT, T., CURRAN, J. E WOOLLACOTT, J. (eds.). Culture, Society and the Media. Londres: Routledge, 1992. 
30 No original: "To suggest that the media should be viewed as 'definers of social reality' is to suggest that what 'events' are 'reported' by the media and the way in which they are signified have a bearing on the ways we perceive the world and thus, [...]o $\mathrm{n}$ the ways in which we act within it. It is to affirm that the media are agencies of mediation, [...] they also propose certain frameworks for the interpretations [...] moulding or structuring our consciousness in ways that are socially and politically consequential. Viewed in these terms, the media are not apart from social reality, passively reflecting and giving back to the world its self-image; they are a part of social reality, contributing to its contours and to the logic and direction of its development via the socially articulated way in which they shape our perceptions" (Bennett, op. cit. p. 288. Grifos no original).
Sugerir que a mídia deva ser vista como "definidora da realidade social" significa sugerir que quais "eventos" sejam "reportados" pela mídia e o modo como os sentidos são atribuídos a eles tenham um peso nos modos como nós percebemos o mundo e, portanto, [...] nos modos como agimos dentro desse mundo. É também afirmar que a mídia é um agente de mediação, [...] que também propõe certas molduras para as interpretações [...] moldando ou estruturando nossas consciências de maneiras que isso implique em consequências sociais e políticas. Vistos desses modos, os meios de comunicação [a mídia] não estão à parte na realidade social, passivamente refletindo e devolvendo para o mundo a sua própria imagem; eles são parte da realidade social, contribuindo para seus contornos e para a lógica e a direção de seu desenvolvimento pela via do modo socialmente articulado como eles formatam nossas percepções ${ }^{30}$.

Embora relevante, o argumento inicial exposto acima exibe resquícios de dualidade entre a "verdade" dos eventos sociais e a "distorção" do enquadramento midiático. Ao defender a ideia de que os meios de comunicação de certo modo condicionam os regimes de significação no modo como editam e apresentam os "fatos", concebe-se um papel ontologicamente secundário à mídia. Esse é o sentido das aspas utilizadas no trecho inicial da citação acima. A objeção do autor sugere que em vez de colocar a questão em termos da oposição entre verdade e falsidade, parece ser mais produtivo investigar a relação de disputa entre diferentes regimes de significação. Tal postura evidencia o aspecto ideológico da produção social de significados. Para Bennett, é preciso situar e tomar uma posição sobre o papel social dos meios de comunicação em relação aos sistemas dominantes de significação.

Sem descurar do viés ideológico, compreende-se que o discurso midiático participa da constituição da realidade ao produzir uma carga afetiva que matiza nossas interações no mundo. Reconhecendo o papel ativo do receptor da comunicação, e o caráter dialético da conformação social dos discursos, entendemos que os discursos sobre o envelhecimento acionados pelos meios de comunicação participam da construção social dos padrões identitários e estilos de vida no contemporâneo.

\section{PARA CONCLUIR}

Diferentemente de outras épocas, quando rígidas normas sociais ditavam os modos de ser em cada idade, o embaralhamento de referências resulta hoje em arranjos identitários diversos e por vezes transitórios. Entretanto, como vimos, para ser socialmente aceito, o velho é instado a manter a disposição e a aparência da juventude. Evidentemente, não há mal algum em cuidar da aparência e é louvável o engajamento em atividades que proporcionem bem-estar físico e mental. O problema começa quando a velhice passa a ser encarada como aquilo que deve ser combatido a qualquer custo. Se a guerra contra o envelhecimento comparece como um imperativo de ordem moral, fica comprometida a dignidade na velhice. 
A ideia da autonomia individual para constituir nossa própria trajetória de vida pode ser celebrada como uma benfazeja mudança em relação aos draconianos imperativos que submetiam nossos antepassados a uma vida social marcada pelo peso da tradição. Na nova cara da terceira idade, os 70 são alardeados como os novos 50. Na cena midiática, a imagem da clássica vovozinha convive com a vovó que tem namorado - ou mesmo namorada.

Pensando nas narrativas sobre o envelhecimento que nos circundam, caberia indagar até que ponto têm sido acionadas, com propriedade, outras imagens mais plurais, menos convencionais, e não obstante dignas - compatíveis com o envelhecimento em nossos dias. A velhice é e sempre foi diversa em termos de como se dão suas vivências e expressões. Como se procurou demonstrar, são múltiplos os atravessamentos que contribuem para modular o processo de envelhecimento que, a rigor, nos acompanha ao longo de toda a vida. Vetores como gênero, classe socioeconômica, raça ou etnia, orientação sexual, afiliação religiosa, cultura familiar, regional e afins tornam problemático o estabelecimento do velho jovem como único - e paradoxal - modelo socialmente aceito como adequado.

De modo inquietante, especula-se que em grande medida os discursos em circulação ainda se fundam nos estereótipos e contribuem para consolidar o

preconceito contra os mais velhos. É preciso nuançar nossa compreensão sobre os pressupostos, apreensões e preconceitos associados ao envelhecimento e à velhice para que os processos de atribuição de significados sejam fecundados por visões que desafiam os estereótipos e associações já sedimentados. Ao atentarmos nesta discussão para a dimensão sociocultural da velhice, é indispensável destacar a importância dos meios de comunicação na constituição das identidades culturais dos mais velhos e nas variadas formas de lidar com a velhice, tanto por parte dos idosos quanto por suas famílias e outras instâncias da sociedade.

Com base nesta inquietação e em uma compreensão da comunicação como aquilo que propicia o tornar comum, no sentido de fazer comunidade, espera-se ter contribuído para colocar em questão essa forma disseminada e sutil de preconceito que necessita ser combatido de modo criativo, incisivo e persistente.

\section{REFERÊNCIAS}

ALONSO, L. E. La era del consumo. Madri: Siglo XXI, 2005.

BEAUVOIR, S. A velhice: a realidade incômoda. São Paulo: Difel, 1976.

BENNETT, T. Media, "Reality", Signification. In: GUREVITCH, M., BENNETT, T., CURRAn, J. e WOOllaCOTT, J. (eds.). Culture, Society and the Media. Londres: Routledge, 1992, p. 287 - 308.

BORGES, G. M.; CAMPOS, M. B.; SILVA, L. G. C. Transição da estrutura etária no Brasil: oportunidades e desafios para a sociedade nas próximas décadas. In: ERVATTI, L. G.; BORGES, G. M.; JARDIM, A. P. Mudança demográfica 
comunicação \& educação • Ano XX • número 2 • jul/dez 2015

no Brasil no início do século XXI: subsídios para as projeções da população. IBGE, 2015, pp. 138-151.

BYTHEWAY, B. Ageism. Buckingham: Open University Press, 2001.

DEBERT, G. G. A reinvenção da velhice: socialização e processos de reprivatização do envelhecimento. São Paulo: Edusp, 1999.

; BRIGUEIRO, M. Fronteiras de gênero e a sexualidade na velhice.

Revista Brasileira das Ciências Sociais, v. 27, n. 80, 2012.

FEATHERSTONE, M.; HEPWORHT, M. Images of Positive Ageing: A Case Study of Retirement Choice Magazine. In: FEATHERSTONE, M.; WERNICK, A. (eds.). Images of Aging: Cultural Representations of Later Life. Londres: Routledge, 1995, pp. 29-47.

FUNDO DE POPULAÇÕES DAS NAÇÕES UNIDAS (UNFPA); HELPAGE INTERNATIONAL. Envelhecimento no século XXI: celebração e desafio. ONU, 2012.

GILLEARD, C. e HIGGS, P. Cultures of Ageing: Self, Citizen and the Body. Londres: Pearson, 2000.

GOES, T. A velhice em novos tempos. Revista E. Sesc-SP, v. 20, n. 1, 2013, pp. 42-43.

GOLDENBERG, M. A bela velhice. Rio de Janeiro: Record, 2013.

(org.). Corpo, envelhecimento e felicidade. Rio de Janeiro: Civilização Brasileira, 2011.

LASLETT, P. A Fresh Map of Life: The Emergence of the Third Age. Londres: Weidenfeld and Nicolson, 1989.

LEAL, M. G. S. Aspectos psicológicos do envelhecimento. Revista E. Sesc-SP, v. 20, n. 1, 2013, pp. 44-46.

NERI, A. L. Atitudes e preconceitos em relação à velhice. In: NERI. A. L. (org.). Idosos no Brasil: vivências, desafios e expectativas na terceira idade. São Paulo: Fundação Perseu Abramo/Sesc-SP, 2007, pp. 33-46.

SLEVIN, K. F. "If I Had Lots of Money... I'd Have a Body Makeover": Managing the Aging Body. Social Forces, v. 88, n. 13, 2010, pp. 1003-1020. 